\title{
Effective surveillance of vector dynamics of Aedes aegypti in a hospital setting in Cuiabá, Mato Grosso, Brazil
}

\author{
Fábio A Leal-Santos, ${ }^{1,2}$, Marinalva BA Santana², Danielle A Figueiredo², Maria M Oliveira², Anágela M \\ Acel $^{2}$, Ana LM Ribeiro ${ }^{2}$, Jorge SV Rodrigues ${ }^{2}$, Danilo Carvalho-Leandro ${ }^{3}$, Rosina D Miyazaki ${ }^{4}$, Diniz P \\ Leite-Jr $r^{2,5}$ \\ ${ }^{1}$ Centro Universitário de Várzea Grande (UNIVAG), Cuiabá, Mato Grosso, Brasil \\ ${ }^{2}$ Laboratório de Entomologia Médica, Faculdade de Medicina, Universidade Federal de Mato Grosso (UFMT), \\ Cuiabá, Mato Grosso, Brasil \\ ${ }^{3}$ Departamento de Zoologia, Universidade de Pernambuco, Departamento de Entomologia, Centro de Pesquisas \\ Aggeu Magalhães, CPqAM FIOCRUZ, Pernambuco, Brasil \\ ${ }^{4}$ Instituto de Biociência/Departamento de Biologia e Zoologia, Universidade Federal de Mato Grosso (UFMT), \\ Cuiabá, Mato Grosso, Brasil \\ ${ }^{5}$ Laboratório de Investigação, Faculdade de Medicina, Universidade Federal de Mato Grosso (UFMT), Cuiabá, \\ Mato Grosso, Brasil
}

\begin{abstract}
Introduction: Hospitals are important for vector control of endemic diseases.

Methodology: To investigate the presence of dengue vectors, 30 locations at a university hospital in Cuiabá, Mato Grosso, Brazil, were monitored from January to December 2009 for mosquito eggs using ovitraps placed in high-traffic internal and external areas.

Results: A total of 2,302 eggs were obtained. Positivity rate at different sites ranged from $50.0 \%$ to $0.0 \%$, with the highest indices in external areas. The presence of eggs correlated with increasing humidity $(\mathrm{r}=9.81 ; \mathrm{p}=0.0013)$.

Discussion: The study aimed to detect and verify the infestation level of the dengue vector and the influence of abiotic factors.

Conclusions: The results indicate that this hospital may be considered an environment for the spread of dengue and hence strategic actions, including control measures and programs aimed at preventing the transmission of this vector, must be implemented.
\end{abstract}

Key words: dengue; Aedes; health surveillance; hospital.

J Infect Dev Ctries 2014; 8(10):1356-1360. doi:10.3855/jidc.4276

(Received 27 September 2013 - Accepted 20 June 2014)

Copyright (C) 2014 Leal-Santos et al. This is an open-access article distributed under the Creative Commons Attribution License, which permits unrestricted use, distribution, and reproduction in any medium, provided the original work is properly cited.

\section{Introduction}

The presence of arthropods in hospitals was first studied in the 1970s. Recently, several studies have been conducted in Brazil [1]. The epidemiological significance of arthropods is not restricted to their role as biological vectors; mechanical vectors must also be considered, since it may be possible to manipulate some of the determinants involved and thus reduce the frequency of the occurrence of the disease in question [1-3]. Poor maintenance of hospital structures increases the occurrence of insect vectors, which enter hospitals through windows, doors, clothes, the sanitation system, and transportation carts [1,3]; vectors have been found throughout hospital premises $[2,4,5]$. To avoid potential problems, constant and routine maintenance and surveillance are required.
Ovitraps are an economical and sensitive method for detecting the presence of Aedes aegypti, especially when infestation is low. Surveys of larval indices are less productive because they may fail to detect the presence of other oviposition sites nearby, and ovitraps are especially useful for early detection of new infestations in areas where mosquitos have been eliminated [6].

The purpose of this study was to assess the level of infestation of $A$. aegypti and the influence of abiotic factors, such as temperature, humidity, and rainfall, within the internal and external areas of the university hospital in Cuiabá city, Mato Grosso, Brazil.

\section{Methodology}

The study was conducted at the university hospital in the city of Cuiabá, State of Mato Grosso, Brazil, 
comprising an area of $18,150 \mathrm{~m}^{2}$, with a constructed area of about $10 \mathrm{~km}^{2}$. Throughout the hospital, 30 capture sites were selected; ovitraps were installed monthly at 15 points in the internal areas and 15 points in the external areas, between January and December 2009. Precipitation, relative humidity, and temperature (maximum and minimum) data were obtained from the National Institute of Meteorology (INMET), which has a station near the university hospital [7].

The oviposition trap described by Reiter [8] was used. Each month, the ovitraps were installed and removed at the end of the collection period; the paddles were transferred for laboratory tests and were then replaced by others in the subsequent month. After counting, the eggs on all paddles were individually immersed in plastic containers $(2 \mathrm{~L})$ with water, for larval eclosion [9].

Larvae were reared under laboratory conditions at a temperature of $27^{\circ} \mathrm{C}$ and a humidity of $75 \%$, and immature mosquitoes were fed using the fish food Alcon Colours. The identification of Aedes species was achieved by observation of fourth-instar larvae mounted on slides under a stereomicroscope (model SZ51 8.0x - 40x, Olympus, Brazil) [10].

All study data were entered and analyzed using the software Epidata (version 3.1) and Microsoft Excel 2010. To analyze the factors associated with oviposition, abiotic factors, the egg positivity index (OPI), and the egg density index (ODI) were compared [9]. Correlations were also calculated for the internal and external areas of the hospital. Correlations were analyzed using Spearman's rank correlation, with a probability error of alpha $=5 \%$.

\section{Results}

A total of 2,302 eggs of $A$. aegypti were obtained at the collection sites during the months studied (Figure 1), with a mean of 191 eggs per month.

The external site with the highest positivity was the maintenance area (site 2 ), with $50 \%$ positivity over the 12 months studied. Other external areas with high positivity were the public access area to the outpatient clinic (site 3); the backyard adjacent to the pathology laboratory access (site 23); and the equipment maintenance area (site 27) (Figure 1).

The sites with the highest indices were in external areas: the obstetrics and gynecology ward (site 13), with $292(12.7 \%)$ eggs; the entrance ambulatory Unified Health System (SUS) (site 03), with 268 (11.6\%) eggs; and the pathology department (site 23), with 187 (8.1\%) eggs.
Figure 1. Distribution of the ovitraps and the number of Aedes aegypti eggs obtained in ovitraps installed between January and December 2009 in a hospital in the city of Cuiabá, Mato Grosso, Brazil. Capture sites numbers: Basement: 18, 19, 23; Ground floor: 1, 2, 3, 4, 5, 6, 7, 8, 9, 20, 21, 22, 24, 25, 26, 27, 28, 29, 30; First floor: 10, 11, 12, 13; Second floor: 14, 15; Third floor: 16, 17.

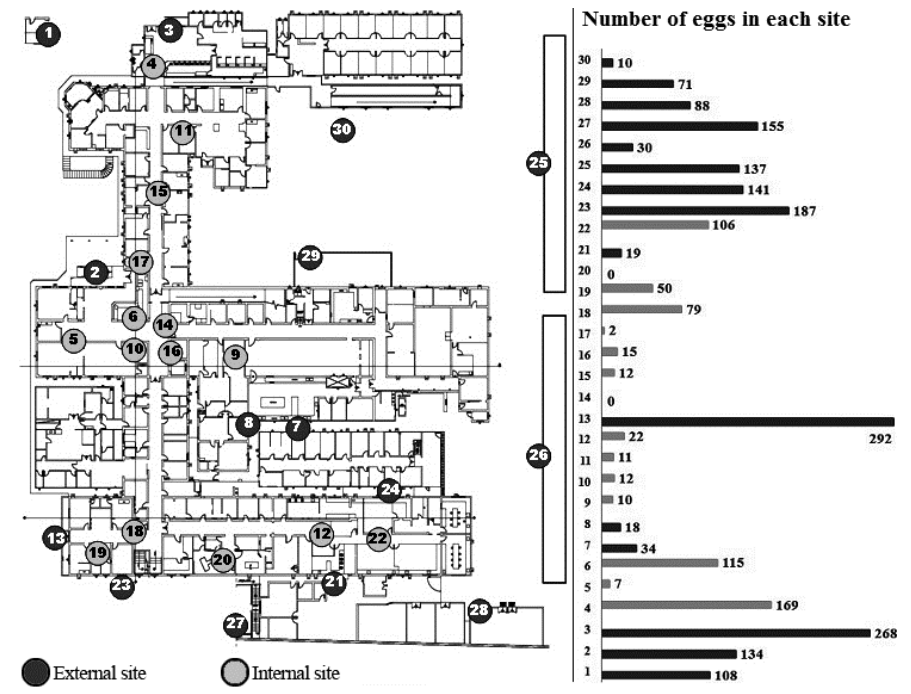

Figure 2. Number of Aedes aegypti eggs, humidity (A) and temperature (B) from January to December 2009 in a hospital in the city of Cuiabá, Mato Grosso, Brazil
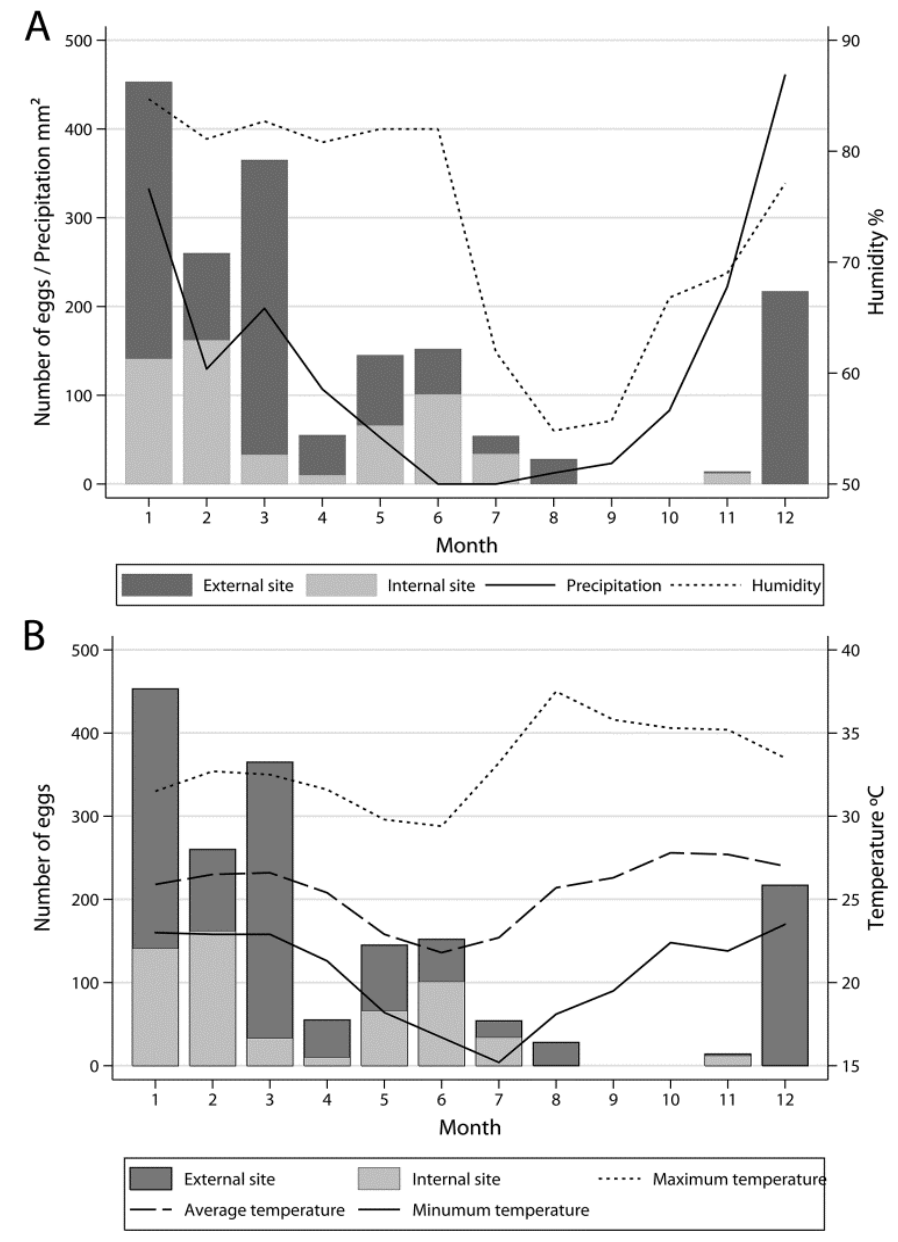
The indoor sites with the highest indices were the public reception area of the outpatient clinic (site 4), with $169(7.3 \%)$ eggs; the private reception area of the outpatient clinic (site 16), with 115 (5.0\%) eggs; and the corridor leading to the clinical laboratory (site 22), with $106(4.6 \%)$ eggs (Figure 1).

Of the 30 points, a strong correlation was observed between four internal and four external points: clinical medical/pathology area $(\mathrm{r}=0.84 ; \mathrm{p}<0.001)$; kitchen/first floor hall $(\mathrm{r}=0.86 ; \mathrm{p}<0.001)$; reception/refectory $(\mathrm{r}=0.89 ; \mathrm{p}<0.001)$; and main entrance/human milk banking $(\mathrm{r}=0.94 ; \mathrm{p}<0.001)$. For other points, it was not possible to confirm a correlation between indoor and outdoor areas, because some places were very isolated and because only a small number of eggs were collected in the study area.

Throughout the study period, the mean number of eggs was significantly greater in the external $(1,692$ eggs) areas than in the indoor (610 eggs) areas ( $p<$ $0.001)$. The mean number of eggs per wood paddle was highest in January (25.8\%), followed by February $(18.33 \%)$ and March (17.29\%). In contrast, no eggs were collected in September or October, and the lowest number of eggs per ovitrap was observed in November (1.13\%) (Figure 2A).

Humidity was the most influential abiotic factor. The presence of eggs was strongly influenced by humidity $(\mathrm{r}=0.81 ; \mathrm{p}=0.0013)$ and negatively influenced by the maximum temperature $(r=-0.70 ; p$ $=0.0117)$. Humidity significantly affected the OPI $(\mathrm{r}=$ $0.87 ; \mathrm{p}=0.0002)$, but the OPI was negatively correlated with maximum temperature $(\mathrm{r}=-0.81 ; \mathrm{p}=$ $0.0013)$. The ODI was also strongly correlated with humidity $(r=0.68 ; \mathrm{p}=0.0158)$ (Figure $2 \mathrm{~B})$.

\section{Discussion}

In 2008, entomological investigations performed in five selected public hospitals in the Philippines admitting dengue patients revealed the presence of only one species, A. aegypti; it was mostly found breeding in fresh water in plant vases, drums, basins, plastic cups, tin cans, and empty paint cans [11].

During much of the year, mosquito eggs were found, which contributed to increased infection and maintenance of this disease. The population density of A. aegypti is directly influenced by the presence of rain. Although a sizeable population may also be maintained during less rainy seasons, through semipermanent breeding sites independent of rainfall, it is during the rainy season that the population achieves the high levels that are important in the transmission of pathogens $[10,12]$.
In a study conducted in the same city, CarvalhoLeandro et al. [3] found that A. aegypti was present in the hospital throughout the study, except for one month. They evaluated the temporal distribution of this mosquito and the influence of environmental variables on egg densities. These studies and our investigation show the relevance of identifying these vectors within health units because these environments provide local health care.

Dengue outbreaks have also been reported in the federal university located in the same city [13]. These studies, also conducted in Cuiabá, showed the presence of vector activity. The hospital is home to a large daily circulating population that may be exposed to the vectors.

Female mosquitoes disperse for two main purposes: to search for blood, a protein source for the development of eggs, and to search for oviposition sites $[13,14]$. A aegypti is thought to have a short flight range of approximately 100 to 500 meters from its oviposition sites [15]. Although internal areas also show the presence of vectors, oviposition does not necessarily occur in these locations. More eggs were collected in external areas than in internal areas, implying that these insects disperse from the outside.

Eggs were more frequently detected in external areas and the consequently greater presence of adult mosquitoes in external areas is due to the increased availability of oviposition sites. This has previously been reported by Brazilian researchers, who highlighted that sources of external domestic reservoirs can provide conditions that favor the maintenance and domiciliation of Aedini populations. In contrast, the study by Carvalho-Leandro et al. [3] showed a higher mean egg density in internal areas compared to external areas.

Rainfall was a determining factor in the colonization of ovitraps by $A$. aegypti, even in those placed indoors. Studies conducted by several researchers [16] have reported that rainfall influences the activities of $A$. aegypti, demonstrating a rapid increase in vector density following rainy periods, with greater availability of sites for reproduction and the consequent rapid eclosion of eggs. The characteristic climate of the state of Mato Grosso is a dry summer and a rainy winter; the study region is classified as savannah, with a hot spring and rare episodes of rain in the drought period between April and September. However, these results can also be explained by the visit from the health and zoonosis surveillance technical team that took place in August 2009, before our collection period for that month, 
resulting in the clean-up and amelioration of certain areas around the hospital, greatly influencing the permanence of oviposition sites, which probably caused the changes observed in subsequent months.

Eggs were never collected from the second-floor reception area (site 14) or the X-ray room (site 20), probably because these locations are well closed and maintained at controlled temperatures, restricting the presence of the vector. Eggs were collected only once from the medical and surgical clinic (site 17), during the month of greatest positivity for mosquito eggs.

In 2009, the Department of Health of the State of Mato Grosso was notified of 52,219 cases and registered approximately 890 confirmed cases of dengue. In Cuiabá city, 9,193 cases of dengue were registered in the same year, the highest number on record [17]. In this year, the hospital studied here registered 134 cases of dengue. However, the occurrence of dengue cases inside and immediately surrounding the hospital could demonstrate the occupational face of this disease, according to a study performed by researchers in Thailand [18].

Several serotypes of the dengue virus (DENV-1, DENV-2, and DENV-3) have been found circulating in Mato Grosso. Results of laboratory tests performed by the Surveillance of Cuiabá on patients from public and private sectors confirmed an outbreak of the viral type DENV-4. Recently, RD Slhessarenko (personal communication, November 15, 2013) identified DENV-4 in A. aegypti collected near the hospital studied here.

The present findings indicate that hospitals could be important locations for dengue dissemination and thus should be considered as strategic areas in actions focused on the prevention of transmission within dengue control programs. As noted here, humidity is the best predictor of the presence of the vector, and the highest prevalence may occur in the lower areas of hospitals. Finally, the presence of this vector in the admission areas of these health units suggests the need for the implementation of control strategies against this vector.

\section{Acknowledgements}

This study was supported by the Fundação de Amparo à Pesquisa do Estado de Mato Grosso (FAPEMAT) and the Laboratory of Entomology, Faculty of Medicine, Federal University of Mato Grosso (UFMT), Cuiabá, Mato Grosso, Brazil.

\section{Authors' contributions}

DPLJ was the researcher-in-chief, and designed and performed the study. DPLJ and FALS were involved in drafting the manuscript. All authors collected and examined the biological samples and were involved in data analysis and drafting of the manuscript. All authors participated in the revision of the manuscript and have read and approved the final version.

\section{References}

1. Daniel M, Srámová H, Absolonová V, Dědicová D, Lhotová H, Masková L, Petras P (1992) Arthropods in a hospital and their potential significance in the epidemiology of hospital infections. Folia Parasitol (Praha) 39: 159-170.

2. Srámová $H$, Daniel $M$, Absolonová $V$, Dědicová $D$, Jedlicková Z, Lhotová H, Petras P, Subertová V (1992) Epidemiological role of arthropods detectable in health facilities. J Hosp Infect 20: 281-292.

3. Carvalho-Leandro D de, Ribeiro ALM, Rodrigues JSV, Albuquerque CMR de, Acel AM, Leal-Santos FA, Leite-Jr DP, Miyazaki RD (2010) Temporal distribution of Aedes aegypti Linnaeus (Diptera, Culicidae), in a Hospital in Cuiabá, State of Mato Grosso, Brazil. Rev Bras Entomol 54: 701-706.

4. Fontana R, Wetler RM da C, Aquino RSS, Andrioli JL, Queiroz GRG, Ferreira SL, Nascimento IC, Delabie JHC (2010) Disseminação de bactérias patogênicas por formigas (Hymenoptera: Formicidae) em dois hospitais do nordeste do Brasil. Neotrop Entomol 39: 655-663.

5. Fowler HG, Bueno OC, Sadatsune T, Montelli AC (1993) Ants as potential vectors of pathogens in hospitals in the state of Sao Paulo, Brazil. Insect Sci its Appl 14: 367-370.

6. Gomes A dos S, Sciavico CJ de S, Eiras ÁE (2006) Periodicidade de oviposição de fêmeas de Aedes aegypti (Linnaeus, 1762) (Diptera: Culicidae) em laboratório e campo. Rev Soc Bras Med Trop 39: 327-332.

7. Instituto Nacional de Meteorologia (2013) Available: http://www.inmet.gov.br/. Accessed 22 October 2013.

8. Reiter P, Amador MA, Colon N (1991) Enhancement of the CDC ovitrap with hay infusions for daily monitoring of Aedes aegypti populations. J Am Mosq Control Assoc 7: 52-55.

9. Gomes C (1998) Medidas dos níveis de infestação urbana para Aedes (Stegomyia) aegypti e Aedes ( stegomyia ) albopictus em programa de vigilância entomológica. Inf Epidemiol SUS 7: 49-57.

10. Consoli RAGB and Lourenço-de-Oliveira R (1994) Principais mosquitos de importância sanitária no Brasil, 2nd edition. Rio de Janeiro: FIOCRUZ. 228 p.

11. Cruz EI, Salazar FV, Aure WE, Torres EP (2008) Aedes survey of selected public hospitals admitting dengue patients in Metro Manila, Philippines. Dengue Bull 32: 171-177.

12. Flauzino RF, Souza-Santos R, Oliveira RM (2011) Socioenvironmental indicators for dengue surveillance in the local level. Saúde e Soc 20: 225-240.

13. Miyazaki RD, Ribeiro ALM, Pignatti MG, Campelo Júnior JH, Pignati M, Campelo JH (2009) Monitoramento do mosquito Aedes aegypti (Linnaeus, 1762) (Diptera: Culicidae), por meio de ovitrampas no Campus da Universidade Federal de Mato Grosso, Cuiabá, Estado de Mato Grosso. Rev Soc Bras Med Trop 42: 392-397. 
14. Gazeta GS, Freire ML, Ezequiel OS, Nunes AJM, Ferreira SV, Norberg AN (2007) Arthropods captured in the environment of hospitals of Rio de Janeiro, Brazil. Rev Patol Trop 36: 254-264.

15. Edman JD, Scott TW, Costero A, Morrison AC, Harrington LC, Clark GG (1998) Aedes aegypti (Diptera: Culicidae) movement influenced by availability of oviposition sites. J Med Entomol 35: 578-583.

16. Glasser CM, Gomes A de C (2002) Clima e sobreposição da distribuição de Aedes aegypti e Aedes albopictus na infestação do Estado de São Paulo. Rev Saude Publica 36: 166-172.

17. Brasil Ministerio da saúde (2013) Sistema de Informação de Agravos de Notificação (SINAN). Sist Informação Agravos Notif. Available: http://dtr2004.saude.gov.br/sinanweb/. Accessed 5 June 2013.
18. Apisarnthanarak A, Mundy LM (2009) Is dengue virus infection an occupational health problem? Clin Infect Dis 48: $135-137$.

\section{Corresponding author}

Diniz Pereira Leite Júnior

Universidade Federal de Mato Grosso, Faculdade de Medicina, Laboratório de Investigação

Avenida Fernando Correa da Costa, 2367 - Boa Esperança

Cuiabá/MT. CEP: 78060-900

Phone: +65 3615-8809

Fax: + 65 3615-8856

Email: djbiologico@gmail.com

Conflict of interests: No conflict of interests is declared. 